\title{
Mastite caprina: seus agentes e sensibilidade frente a antimicrobianos
}

\section{Goat mastitis: theirs agents and susceptibility face to the antimicrobial}

\author{
Helio Langoni, ${ }^{*}$ Paulo Francisco Domingues, ${ }^{*}$ Simone Baldini*
}

\begin{abstract}
Resumo
Examinaram-se 124 amostras de leite de cabras das raças Saanen, Parda Alpina e Toggenburg com mastite subclínica, diagnosticada pelo teste "California Mastitis Test" (CMT), escore 3+. Realizaram-se cultivos bacteriológicos em meios de ágarsangue e MacConkey, sendo que os microrganismos isolados foram identificados por esfregaços corados pelo método de Gram e provas taxonômicas. Em seguida, submetidos ao teste de sensibilidade bacteriana in vitro. Isolou-se um total de 140 microrganismos em cultura pura e em associação, distribuídos da seguinte maneira: Staphylococcus epidermidis $(\mathrm{n}=70$; $50,0 \%)$, Streptococcus agalactiae $(n=19 ; 13,6 \%)$, Staphylococcus aureus $(n=16 ; 11,4 \%)$, Corynebacterium bovis $(n=12$; $8,6 \%)$, Candida albicans $(n=7 ; 5,0 \%)$, Bacillus spp $(n=7 ; 5,0 \%)$, Pasteurella multocida $(n=5 ; 3,6 \%)$, Escherichia coli $(n=2$; $1,4 \%)$, Acinetobacter calcoaceticus $(n=2 ; 1,4 \%$ ). No teste de sensibilidade in vitro aos antimicrobianos observou-se que Staphylococcus epidermidis, Staphylococcus aureus, Streptococcus agalactiae e Corynebacterium bovis, foram os microrganismos isolados com maior freqüência, sendo a oxacilina e gentamicina as drogas de melhor eficácia.
\end{abstract}

Palavras-chave: caprinos, mastite, microrganismos, antibióticos.

\begin{abstract}
A total of 124 samples of milk of Saanen, Parda Alpina and Toggenburg goats was examined with subclinical mastitis, diagnosed by the test "California Mastitis Test " (CMT). Took place bacteriological culture in Blood Agar Base and MacConkey Agar, and the isolated microorganisms was identified smear colored by the method of Gram and taxonomy prove. Soon after, submitted to the test of in vitro antibacterial susceptibility. A total of 140 microorganisms was isolated in pure culture and in association, distributed in the following way: Staphylococcus epidermidis $(n=70 ; 50,0 \%)$, Streptococcus agalactiae $(n=19 ; 13,6 \%)$, Staphylococcus aureus $(n=16 ; 11,4 \%)$, Corynebacterium bovis $(n=12 ; 8,6 \%)$, Candida albicans $(n=7 ; 5,0 \%)$, Bacillus spp $(n=7 ; 5,0 \%)$, Pasteurella multocida $(n=5 ; 3,6 \%)$, Escherichia coli $(n=2 ; 1,4 \%)$, Acinetobacter calcoaceticus $(n=2 ; 1,4 \%)$. The test of antibacterial susceptibility to the antibiotics was observed that for Staphylococcus epidermidis, Staphylococcus aureus, Streptococcus agalactiae and Corynebacterium bovis that were the agents isolated with larger frequency, the oxacilin and gentamicin and were the drugs of better effectiveness.
\end{abstract}

Keywords: goat, mastitis, microorganisms, antibiotics.

\section{Introdução}

A mastite é a inflamação da glândula mamária, em geral provocada pela presença de microrganismos, promovendo alterações na composição do leite e com taxas elevadas de células somáticas.

O leite de cabra é um alimento de alto valor nutritivo indicado inclusive para indivíduos que sofrem de problemas digestivos e que não toleram o leite bovino. Com o aprimoramento da criação de caprinos e o aumento na produção leiteira, tem surgido uma maior preocupação com a qualidade do leite, o que requer o controle de alguns fatores que possam alterar suas características, e o principal deles é a mastite.

A mastite caprina, assim como a bovina, gera graves prejuízos econômicos devido ao descarte do leite, custos com medi- camentos e assistência veterinária, aumento da mão-deobra, redução da qualidade e quantidade do leite e seus subprodutos (Dulin et al., 1983; Barros e Leitão, 1992) além de ser importante problema de saúde pública (Guss, 1975).

Dentre os agentes etiológicos identificados da mastite caprina, a maioria é similar aos encontrados na espécie bovina, entre eles Staphylococcus coagulase positiva e negativa, Streptococcus spp, Escherichia coli, Micrococcus spp, Pasteurella spp (Manser, 1986; Stehling et al., 1986; Barcellos et al., 1987; Guha e al., 1989; Maisi \& Riipinen, 1991; De Castro et al., 1992; Da Silva et al., 1996b).

$\mathrm{Na}$ forma subclínica da doença, os Staphylococcus coagulase negativa têm sido isolados com mais freqüência (Poutrel e Lerondelle, 1983; Da Silva et al., 1996b; Poutrel et al., 1997).

* Professores do Departamento de Higiene Veterinária e Saúde Pública, FMVZ, UNESP, Campus de Botucatu - CEP:18618-000, Botucatu, SP. email: hlangoni@fmvz.unesp.br 
Meireles et al. (1999) trabalhando com monitoramento microbiológico em amostras de leite caprino, observaram o isolamento de Staphylococcus epidermidis, Staphylococcus aureus e Streptococcus agalactiae em $76,50 \%, 47,10 \%$ e $29,40 \%$, respectivamente.

Tendo em vista a importância desta afecção e o interesse pela caprinocultura, estudou-se a ocorrência da mastite, a sua etiologia, e a sensibilidade in vitro aos antibióticos dos microrganismos isolados de amostras de leite de cabras com infecção subclínica.

\section{Material e método}

Examinaram-se 124 amostras de leite, provenientes de 62 cabras em lactação, das raças Saanen, Parda Alpina e Toggenburg com mastite subclínica, em capril localizado no município de Botucatu, estado de São Paulo. A mastite foi diagnosticada mediante o uso do California Mastitis Test (CMT), segundo Schalm e Noorlander (1957), considerandose os quartos mamários positivos com escore $3+$.

Para a colheita das amostras de leite, os tetos foram lavados previamente com água e secados com toalha de papel descartável. A seguir, fezse anti-sepsia do óstio do teto com álcool a $70 \%$ e as amostras colhidas em frascos de vidro esterilizados e encaminhadas ao laboratório do Núcleo de Pesquisa em Mastites - NUPEMAS, da Faculdade de Medicina Veterinária e Zootecnia, UNESP, Campus de Botucatu, sob refrigeração, em caixa isotérmica contendo gelo reciclável.

No laboratório, realizaram-se cultivos microbiológicos com $0,01 \mathrm{~mL}$ de leite em placas de Petri contendo meios de ágarsangue ovino a $5 \%$ e MacConkey, incubando-se a $37^{\circ} \mathrm{C}$. As leituras das placas foram realizadas às 24,48 e 72 horas, observando-se a morfologia das unidades formadoras de colônias (UFC) e, a seguir, preparadas lâminas com

Tabela 2: Número de microrganismos isolados em associação de amostras de leite de cabras com mastite subclínica, Botucatu, SP

\begin{tabular}{lcc}
\hline Microrganismos & Número & $\%$ \\
\hline Staphylococcus epidermidis + Streptococcus agalactiae & 06 & 40,0 \\
Staphylococcus epidermidis + Bacillus spp & 02 & 13,3 \\
Staphylococcus epidermidis + Corynebacterium bovis & 02 & 13,3 \\
Corynebacterium bovis + Bacillus spp & 02 & 13,3 \\
Staphylococcus aureus + Corynebacterium bovis & 01 & 6,7 \\
Streptococcus agalactiae + Corynebacterium bovis & 01 & 6,7 \\
Staphylococcus aureus, Streptococcus agalactiae e Acinetobactercalcoaceticus & 01 & 6,7 \\
\hline Total & 15 & 100,0 \\
\hline
\end{tabular}

Tabela 1 - Número de microrganismos isolados em cultura pura de amostras de leite de cabras com mastite subclínica, Botucatu, SP

\begin{tabular}{lcc}
\hline Microrganismos & Número & $\%$ \\
\hline Staphylococcus epidermidis & 60 & 55,0 \\
Staphylococcus aureus & 14 & 12,8 \\
Streptococcus agalactiae & 11 & 10,1 \\
Candida albicans & 07 & 6,4 \\
Corynebacterium bovis & 06 & 5,5 \\
Pasteurella multocida & 05 & 4,6 \\
Bacillus spp & 03 & 2,8 \\
Escherichia coli & 02 & 1,8 \\
Acinetobacter calcoaceticus & 01 & 1,0 \\
\hline Total & 109 & 100,0 \\
\hline
\end{tabular}

esfregaços corados pelo método de Gram, para verificar-se ao microscópio, a morfologia bacteriana e sua característica tintorial. Os microrganismos foram transferidos para meio de caldo cérebro-coração (BHI) para realização das provas taxonômicas, segundo Carter e Cole Junior (1990) e Quinn et al. (1994) e os testes de sensibilidade in vitro, de acordo com Bauer et al. (1966), em placas contendo Agar de Mueller-Hinton. Quando o agente a ser testado era Streptococcus spp ou Corynebacterium bovis, foram utilizadas placas com o mesmo meio de cultura enriquecido de $10 \%$ de sangue bovino para facilitar o crescimento destes microrganismos.

\section{Resultados}

Os resultados do isolamento de microrganismos em cultura pura e em associação podem ser observados nas Tabelas 1 e 2 , respectivamente.

$\mathrm{Na}$ Tabela 3 observa-se o total de microrganismos isolados das amostras de leite de cabras com mastite subclínica.

$\mathrm{Na}$ Tabela 4 estão inseridos os resultados do teste de sensibilidade bacteriana in vitro frente aos antibióticos e quimioterápicos.
Tabela 3 - Número total de microrganismos isolados em cultura pura e em associação de amostras de leite de cabras com mastite subclínica, Botucatu, SP

\begin{tabular}{lcc}
\hline Microrganismos & Número & $\%$ \\
\hline Staphylococcus epidermidis & 70 & 50,0 \\
Streptococcus agalactiae & 19 & 13,6 \\
Staphylococcus aureus & 16 & 11,4 \\
Corynebacterium bovis & 12 & 8,6 \\
Candida albicans & 07 & 5,0 \\
Bacillus spp & 07 & 5,0 \\
Pasteurella multocida & 05 & 3,6 \\
Escherichia coli & 02 & 1,4 \\
Acinetobacter calcoaceticus & 02 & 1,4 \\
\hline Total & 140 & 100,0 \\
\hline
\end{tabular}


Tabela 4: Resultado do teste de sensibilidade in vitro para Staphylococcus epidermidis, Streptococcus agalactiae, Staphylococcus aureus e Corynebacterium bovis isolados de amostras de leite de cabras com mastite subclínica, Botucatu, SP

\begin{tabular}{lcccc}
\hline Antimicrobiano & $\begin{array}{c}\text { S. epidermidis }(70)^{*} \\
\%\end{array}$ & $\begin{array}{c}\text { S.agalactiae (19) } \\
\%\end{array}$ & $\begin{array}{c}\text { S. aureus (16) } \\
\%\end{array}$ & $\begin{array}{c}\text { C.bovis (12) } \\
\%\end{array}$ \\
\hline Ampicilina & 34,8 & 63,1 & 25,0 & 75,0 \\
Cefalosporina & 77,1 & 78,9 & 81,2 & 75,0 \\
Gentamicina & 91,6 & 89,4 & 93,7 & 83,3 \\
Neomicina & 38,5 & 52,6 & 37,5 & 58,3 \\
Nitrofurantoina & 81,4 & 63,1 & 62,5 & 66,6 \\
Oxacilina & 91,9 & 84,2 & 93,7 & 91,6 \\
Penicilina & 38,5 & 21,0 & 12,5 & 16,6 \\
Tetraciclina & 70,0 & 68,4 & 75,0 & 75,0 \\
\hline Número de
\end{tabular}

* Número de amostras, e respectiva porcentagem de amostras sensíveis.

\section{Discussão e conclusão}

Das 124 amostras de leite examinadas, observou-se que 109 $(87,9 \%)$ apresentaram crescimento bacteriano, enquanto 15 $(12,1 \%)$ mostraram-se negativas. Estas culturas negativas poderiam estar relacionadas, provavelmente, com as mastites assépticas ou tratar-se de agentes que exigem condições especiais para o seu isolamento.

$\mathrm{Na}$ Tabela 1 pode ser observado que os microrganismos isolados em cultura pura foram: Staphylococcus epidermidis $(55,0 \%)$, Staphylococcus aureus $(12,8 \%)$, Streptococcus agalactiae (10,1\%), Candida albicans $(6,4 \%)$, Corynebacterium bovis (5,5\%), Pasteurella multocida (4,6\%), Bacillus spp (2,8\%), Escherichia coli $(1,8 \%)$ e Acinetobacter calcoaceticus (1,0\%).

$\mathrm{Na}$ Tabela 2 verifica-se que a associação mais freqüente foi entre o Staphylococcus epidermidis e o Streptococcus agalactiae $(40,0 \%)$.

Os microrganismos isolados com mais freqüência foram: Staphylococcus epidermidis (50,0\%), Streptococcus agalactiae $(13,6 \%)$, Staphylococcus aureus $(11,4 \%)$ e Corynebacterium bovis $(8,6 \%)$, conforme a Tabela 3 .

Observou-se no estudo de sensibilidade bacteriana frente a diferentes drogas antimicrobianas que Staphylococcus epidermidis, Streptococcus agalactiae, Staphylococcus aureus e Corynebacterium bovis, foram os agentes isolados com maior freqüência, sendo a oxacilina e gentamicina os antibióticos que apresentaram melhor ação inibitória (Tabela 4).

Da Silva et al. (1996b), estudando 2.490 amostras de leite de 238 cabras, observaram o isolamento de microrganismos

\section{Agradecimentos}

Ao Sr. Fernando José Paganini Listoni, Técnico de Laboratório, pelos relevantes serviços laboratoriais. em $85,3 \%$ dos cultivos realizados, resultado similar ao observado no presente trabalho, que foi de $87,9 \%$. Quanto ao patógeno isolado com maior freqüência, estes autores encontraram para o Staphylococcus epidermidis $(77,0 \%)$, uma porcentagem maior do que o presente estudo, que foi de $55,0 \%$.

Os resultados de Meireles et al. (1999) corroboram com os da presente pesquisa quanto à importância do Staphylococcus epidermidis, Staphylococcus aureus e Streptococcus agalactiae nas infecções intramamárias na espécie caprina, o que reforça o significado de agentes contagiosos na etiologia das mastites nesta espécie, e nos faz alertar para a importância dos processos de desinfecção para o controle das mastites em caprinos, ou seja, imersão dos tetos em desinfetantes antes e após a ordenha, bem como adequada higienização dos copos (insufladores) da ordenhadeira mecânica e mãos do ordenhador, quando se tratar de ordenha manual.

Guha et al. (1989) estudando a incidência e sensibilidade antimicrobiana de microrganismos isolados de amostras de leite de cabras, verificaram as seguintes porcentagens de isolamento Staphylococcus spp (57,9\%), Streptococcus spp $(36,8 \%)$ e Escherichia coli $(5,26 \%)$. Estas porcentagens diferem do nosso estudo quanto ao Streptococcus spp e Escherichia coli; entretanto, são similares para o Staphylococcus spp. No teste de sensibilidade in vitro, a gentamicina, à semelhança do nosso estudo, foi um dos antibióticos que se mostraram mais eficaz frente aos principais microrganismos isolados.

Quanto à utilização do CMT em amostras de leite de cabras, sabe-se que a exatidão do teste é duvidosa devido à presença de células epiteliais que, juntamente com os leucócitos, reagem ao teste causando uma interpretação diferente da usada para bovinos (Barcellos et al. 1987).

Da Silva et al. (1996a) citam que os resultados de CMT 2+e $3+$ podem ser considerados como indicativos de infecção na espécie caprina. Entretanto, para uma maior segurança, o teste bacteriológico deve ser utilizado como o procedimento realizado na presente pesquisa.

Conclui-se que estudos como este fornecem dados quanto à etiologia e sensibilidade in vitro dos microrganismos frente aos antibióticos e, portanto, devem ser utilizados em programas de controle e tratamento desta afecção em cabras, resultando em maior produção leiteira e melhor qualidade do leite, do ponto de vista sanitário. 


\section{Referências}

BARCELLOS, T.F.S., SILVA, N., MARQUES JÚNIOR, A.P. Mamite caprina em rebanhos próximos a Belo Horizonte-Minas Gerais. I - Etiologia e sensibilidade a antibióticos. II-Métodos de diagnóstico. Arq. Bras. Med. Vet. Zootec., v. 39, p. 307-315, 1987.

BARROS, G.C., LEITÃO, C.H. Influência da mastite sobre as características físico-químicas do leite de cabra. Pesq. Vet. Bras., v. 12, p. 45-48, 1992.

BAUER, A.W., KIRBY, W.M., SHERRIS, J.C., TURCK, M. Antibiotic susceptibility testing by a standardized single disk method. American Journal Clinical Pathology, v. 45, p. 493-496, 1966.

CARTER, G.R., COLE JUNIOR, J.R. Diagnostic procedures in veterinary bacteriology and mycology. 5. ed. New York: Academic Press, 1990. $620 \mathrm{p}$.

DASILVA, E.R., SAUKAS, T.N., ALVES, F.S.F., PINHEIRO, R.R. Contagem de células somáticas e California Mastitis Test no diagnóstico da mastite caprina subclínica. Rev. Bras. Med. Vet., v. 18, p.78-83, 1996a.

DA SILVA, E.R., ALVES, F.S.F., PINHEIRO, R.R., SAUKAS, T.N., PIRES, P.C., DA SILVA, F.M.P. Flora microbiológica do leite de cabras de diferentes sistemas de produção. Congresso Brasileiro de Medicina Veterinária, 24., 1996. p. 205. Anais ... Goiânia, GO, Sociedade Goiana de Veterinária. 1996b.

DE CASTRO, M.V., LANGENEGGER, M.C.E.H., LANGENEGGER, J. Ocorrência e caracterização de estafilococos coagulase negativos em leite de cabras no Estado do Rio de Janeiro. Semina, v. 13, p. 1517, 1992.

DULIN, A.M., PAAPE, M.J. SCHULTZE, W.D., WEINLAND, B.T. Effect of parity, stage of lactation, and intramammary infection on concentration of somatic cells and cytoplasmic particles in goat milk. J. Dairy Sci., v. 66, p. 2426-2433, 1983.
GUHA, C., PRAMANIK, A.K., MISSRA, S.K., BANERJEE, A.K. Studies on the incidence and diagnosis of sub-clinical and clinical mastitis in goats and in vitro sensitivity of the isolated pathogens. Indian Vet. J., v. 66, p. 601-604, 1989.

GUSS, S.B. Dairy goat herd health problems. J. Am. Vet. Med. Assoc., v. 167, p.1076-1079, 1975.

MAISI, P., RIIPINEN, I. Pathogenicity of different species of staphylococci in caprine udder. Br. Vet. J., v. 147, p.126-132, 1991.

MANSER, P.A. Prevalence, causes and laboratory diagnosis of subclinical mastitis in the goat. Vet. Rec., v. 118, p.552-554, 1986.

MEIRELES, I.R., GOTTSCHALK, S., DA SILVA, A.V., CABRAL, K.G., LANGONI, H. Monitoramento microbiológico e avaliação de provas diagnósticas na mastite caprina. Napgama, v. 6, p. 17-19, 1999.

POUTREL, B., LERONDELLE, C. Cell content of goat milk: California Mastitis Test, coulter counter, and fossomatic for predicting half infection. J. Dairy Sci., v. 66, p. 2575-2579, 1983.

POUTREL, B., CRÉMOUX, R., DUCELLIEZ, M., VERNEAU, D. Control of intramammary infections in goats: impact on somatic cell counts. J. Anim. Sci., v. 75, p. 566-570, 1997.

QUINN, P.J., CARTER, M.E., MARKEY, B. et al. Mastitis. In: Clinical Veterinary Microbiology. London: Mosby-Year Book Europe Limited, 1994. Cap. 36, p. 327-344.

SCHALM, O.W., NOORLANDER, D.D. Experiments and observations leading to development of the California Mastitis Test. Journal American Veterinary Medical Association., v. 130, p. 199-204, 1957.

STEHLING, R.N., VARGAS, O.L., SANTOS, E.C., DUARTE, R.M. Estudo da evolução da mastite caprina induzida por enterotoxina estafilocócica e estreptocócica. Arq. Bras. Med. Vet. Zootec., v. 38, p. 701-717, 1986. 